\title{
Intrinsic Neuromodulation in the Tritonia Swim CPG: The Serotonergic Dorsal Swim Interneurons Act Presynaptically to Enhance Transmitter Release from Interneuron C2
}

\author{
Paul S. Katz and William N. Frost \\ Department of Neurobiology and Anatomy, University of Texas Medical School, Houston, Texas 77030
}

Heterosynaptic enhancement of transmitter release is potentially very important for neuronal computation, yet, to our knowledge, no prior study has shown that stimulation of one neuron directly enhances release from an interneuron. Here, we demonstrate that in the marine mollusk Tritonia diomedea, the serotonergic dorsal swim interneurons (DSIs) heterosynaptically increase the amount of transmitter released from another interneuron, $\mathrm{C2}$. Stimulation of a single DSI at physiological firing frequencies increases the size of synaptic potentials evoked by $\mathrm{C}_{2}$. This increase in synaptic efficacy is correlated with an increase in homosynaptic paired-pulse facilitation by $\mathrm{C} 2$. Thus, it is likely to be due to an enhancement of transmitter release from $\mathrm{C}_{2}$, rather than a postsynaptic action on the followers of $\mathrm{C}_{2}$. This is further supported by the fact that DSI stimulation enhances the strengths of all chemical synapses made by C2 within the swim network, regardless of their sign. Furthermore, DSI enhances the amplitude of C2 synaptic potentials recorded in neurons that DSI itself does not synapse with. Finally, DSI differentially modulates different synaptic inputs to the same postsynaptic target; while increasing C2-evoked EPSPs it simultaneously decreases the size of EPSPs evoked by other DSIs. The heterosynaptic facilitation of $\mathrm{C} 2$ synaptic potentials by $\mathrm{DSI}$ is not caused by a simple depolarization of $\mathrm{C} 2$, but may be a direct action on the transmitter release mechanism. This neuromodulatory effect, which is intrinsic to the circuitry of the central pattern generator for escape swimming in Tritonia, may be important for self-reconfiguration of the swim motor network.

[Key words: 5-HT, heterosynaptic facilitation, nudibranch mollusk, presynaptic mechanism, neuromodulation, central pattern generator]

Heterosynaptic regulation of neurotransmitter release allows a level of fine control for neuronal circuits. For example, reduction of transmitter release from primary sensory neurons by presyn-

\footnotetext{
Received Jan. 30, 1995; revised Apr. 24, 1995; accepted Apr. 28, 1995.

We thank Dr. M. Nusbaum for his helpful comments and Dr. Mark Tunstall and Travis Hoppe for their careful reading of the manuscript and helpful suggestions. We thank Dr. A. O. D. Willows for providing space at the Friday Harbor Laboratories, University of Washington, where portions of this research were conducted. This work was supported by NIH Grants R01 MH49563 and R29 MH48536.

Correspondence should be addressed to Paul S. Katz, Department of Neurobiology and Anatomy, University of Texas Medical School, 4.O. Box 20\%08, Houston, TX 77225 .

Copyright (C) 1995 Society for Neuroscience 0270-6474/95/156035-11\$05.00/0
}

aptic inhibition is a nearly ubiquitous mechanism for gating afferent input to central circuits (Sillar, 1991; Watson, 1992; Nusbaum, 1994). Similarly, enhancement of transmitter release from sensory neurons via heterosynaptic facilitation is involved in sensitization of reflexes in mollusks (Hawkins et al., 1981; Mackey et al., 1989; Byrne et al., 1991). Presynaptic enhancement of release is potentially an important mechanism of plasticity in interneuronal circuits as well. Yet, surprisingly we have been unable to find examples wherc ncuromodulatory ncurons have been directly shown to enhance transmitter release from interneurons. There are many cases where application of exogenous neuromodulatory substances have been shown to cause an increase in neurotransmitter release from neurons (Langer, 1980; Kravitz et al., 1981; Chesselet, 1984; Starke et al., 1989; Delaney et al., 1991; Mintz and Korn, 1991; Cameron and Williams, 1993; Gereau and Conn, 1994; Katz et al., 1994). Although it would appear likely that the neuronal sources of these substances would have similar effects, the evidence that neuron al activity can heterosynaptically enhance release from interneurons is, at present, still indirect (Shimahara and Tauc, 1976; Mintz et al., 1989; Mintz and Korn, 1991). Here we demonstrate that serotonergic interneurons intrinsic to a central pattern generator (CPG) circuit in the mollusk, Tritonia diomedea, enhance transmitter release from another CPG interneuron.

Most examples of neuromodulation in motor systems involve sources of neuromodulatory input extrinsic to the local circuit (Harris-Warrick, 1988; Katz and Harris-Warrick, 1990; HarrisWarrick and Marder, 1991; Jordan et al., 1992; Orchard et al., 1993). However, in some systems neuromodulation is intrinsic to the local circuit itself (Cropper et al., 1987; Willows et al., 1988; Nusbaum et al., 1992; Barnes et al., 1994; Katz et al., 1994; Marder, 1994). When the modulatory neurons are extrinsic to the local circuit, the circuit can operate in modulated or unmodulated inodes. Furthermore, different extrinsic sources of neuromodulation can affect the circuit at different times, reflecting activity states in other parts of the nervous system. In contrast, when neuromodulation is intrinsic to the circuit it potentially is always present, and the level of modulation is intimately linked to the level of neuronal activity within the circuit itself.

Neuromodulation is intrinsic to the CPG that controls escape swimming in the nudibranch mollusk, Tritonia. Tritonia is a bottom-dwelling marine sea slug that produces an escape swim in response to contact by a predatory starfish (Willows and Hoyle, 1969; Willows et al., 1973a; Getting, 1983a; Getting and Dekin, 1985a). The escape swim, consisting of a prolonged series of ventral and dorsal whole-body flexions, is generated by a CPG circuit formed by premotor interneurons (Taghert and 

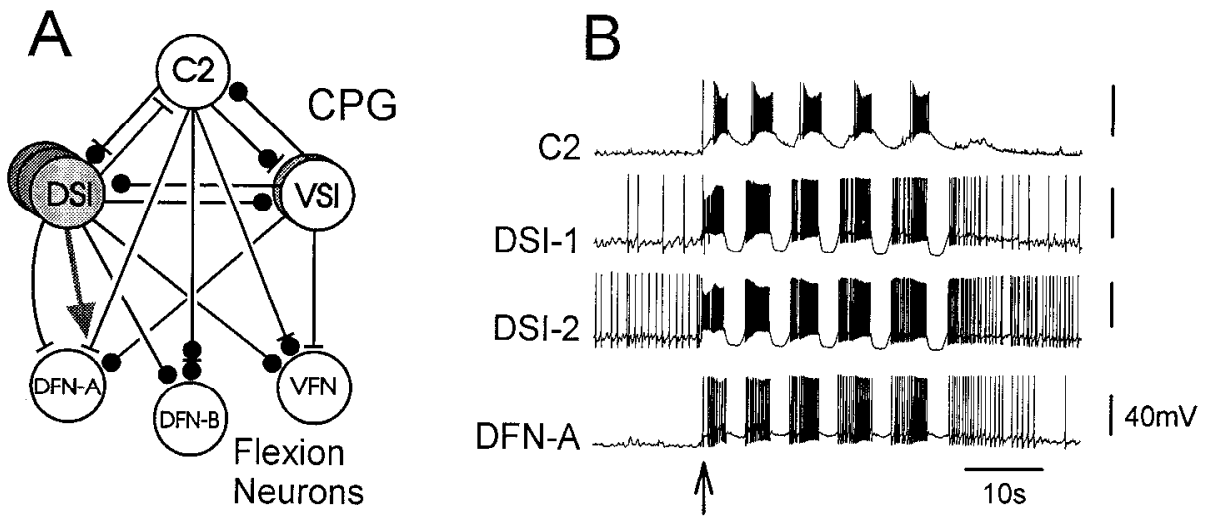

Figure 1. The Tritonia swim network and swim motor program. A, A simplified wiring diagram showing the important connections among the central pattern generator $(C P G)$ neurons, the dorsal swim interneurons (DSI), ventral swim interneurons (VSI), and cerebral neuron $2(C 2)$ and their connections to the efferent flexion neurons: the dorsal flexion neurons ( $D F N-A, D F N-B)$ and the ventral flexion neurons (VFN) (Getting et al., 1980; Getting, 1981, 1983b; Hume and Getting, 1982). There are three DSIs and two VSIs and a single C2 on each side of the brain. DSI modulates the strength of the connection from C2 to DFN-A (denoted by arrow). Bars indicate excitatory synapses; circles are inhibitory synapses. Multicomponent synapses are shown as combinations of bars and circles. $B$, An example of the swim motor program generated by stimulation of pedal nerve $3(10 \mathrm{~Hz}, 1 \mathrm{sec}$ at arrow). Simultaneous intracellular recordings show that C2, two DSIs, and a DFN-A exhibited five cycles of action potential bursts, which would underlie five cycles of swim activity in the intact animal.

Willows, 1978; Getting et al., 1980; Getting, 1981, 1983b, 1989a) (Fig. 1). These interneurons, the dorsal swim interneurons (DSI-A,B,C), the ventral swim interneurons (VSI-A,B), and peptidergic cerebral neuron 2 (C2), synapse with efferent flexion neurons (Hume and Getting, 1982; Hume et al., 1982) (Fig. 1A). Recently, the DSIs were shown to be 5-HT immunoreactive and to have neuromodulatory effects in addition to their classical synaptic actions (Katz et al., 1994; McClellan et al., 1994); stimulation of a single DSI at physiological firing frequencies enhances the amplitude of the synaptic potentials evoked by $\mathrm{C} 2$ onto other DSIs and onto DFN-A (Katz et al., 1994). This neuromodulatory effect is due to the actions of 5-HT released from DSI (Katz and Frost, 1993). Determining whether DSI acts presynaptically on $\mathrm{C} 2$ to enhance release of its neurotransmitter, or postsynaptically on the targets of $\mathrm{C} 2$ to enhance their responsiveness to $\mathrm{C} 2$, has important implications for the organization and function of the modulation in the swim network.

Portions of this work have been previously presented in abstract form (Katz and Frost, 1994).

Table 1. List of C2 and DSI synaptic connections in the swim network and the effect of DSI stimulation on C2-evoked PSPs

\begin{tabular}{llll}
$\begin{array}{l}\text { Post- } \\
\text { synaptic } \\
\text { neuron }\end{array}$ & $\begin{array}{l}\text { C2 } \\
\text { synaptic } \\
\text { action }\end{array}$ & $\begin{array}{l}\text { DSI } \\
\text { synaptic } \\
\text { action }\end{array}$ & $\begin{array}{l}\text { DSI } \\
\text { enhancement } \\
\text { of C2- } \\
\text { evoked } \\
\text { PSP? }\end{array}$ \\
\hline DSI-A & I & E & Yes $(n=2)$ \\
DSI-B,C & E-I & E & Yes $(n=11)^{a}$ \\
VSI-A & I-E & E-I-E & Yes $(n=3)$ \\
VSI-B & E-I & I & Yes $(n=2)$ \\
DFN-A & E & E & Yes $(n=48)^{a}$ \\
DFN-B & I-E-I & I-I & Yes $(n=3)$ \\
VFN & E-I & I & Yes $(n=4)$
\end{tabular}

I, Inhibitory; E, excitatory; multicomponent synapses are displayed as com binations of $\mathrm{E}$ and $\mathrm{I}$.

"Includes some data from Katz et al., 1994.

\section{Materials and Methods}

Tritonia diomedea were obtained from the intracoastal waters of Washington State and British Columbia. The central ganglia, consisting of the fused cerebro-pleural and pedal ganglia, were dissected from the animal as described elsewhere (Willows et al., 1973b) and pinned in a Sylgard-lined chamber containing normal saline chilled to $2^{\circ} \mathrm{C}$. Normal saline consisted of (in $\mathrm{mM}$ ): $420 \mathrm{NaCl}, 10 \mathrm{KCl}, 10 \mathrm{CaCl}_{2} 50 \mathrm{MgCl}_{2}, 10$ HEPES ( $\mathrm{pH} 7.6$ ), and $11 \mathrm{D}$-glucose. Throughout the experiment the ganglia were continuously superfused with cooled saline.

To facilitate multiple microelectrode penetrations, the ganglionic connective tissue sheath was removed using fine forceps and scissors. Suction electrodes were placed on left and right pedal nerves 3 (Willows et al., 1973b) for use in nerve stimulation to evoke swim motor programs. A suction electrode on the pedal-pedal commisure (pedal nerve 6) was used to monitor C2 spike activity (Longley and Longley, 1987). Following the dissection and placement of suction electrodes, the preparation was warmed to $10^{\circ} \mathrm{C}$ and left to rest for at least $3 \mathrm{hr}$ to allow any long-term physiological effects of the dissection procedure to dissipate. All experiments were conducted at $10^{\circ} \mathrm{C}$.

Neurons were impaled with glass microelectrodes $(8-20 \mathrm{M} \Omega)$ filled with $4 \mathrm{M} \mathrm{K}$ acetate and inserted into electrode chucks filled with $3 \mathrm{M}$ $\mathrm{KCl}$. Neurons were identified based on soma location and coloration, activity at rest and during a swim motor program, and synaptic connectivity (Willows et al., 1973b; Taghert and Willows, 1978; Getting et al., 1980; Hume and Getting, 1982; Getting, 1983b). The CPG interneurons (C2, DSI, and VSI-A) have their somata on the dorsal surface of the cerebral ganglion (Getting et al., 1980). The cell body of VSI-B is located beneath the ventral surface of the pleural ganglion (Getting, 1983b). The efferent flexion neurons (DFN-A,B and VFN) are located in the adjoining pedal ganglion (Hume et al., 1982). All of the neurons have contralateral homologs. The CPG interneurons project to the contralateral pedal ganglion (Getting et al., 1980), and it is thus likely that they synapse near the somata of the flexion neurons; however, none of the synapses have been anatomically located.

After identifying the neurons, the superfusion medium was switched to high divalent cation saline to reduce the contribution of polysynaptic pathways to any responses seen. All experiments were conducted in high divalent cation saline which consisted of (in $\mathrm{mM}$ ): $285 \mathrm{NaCl}, 10$

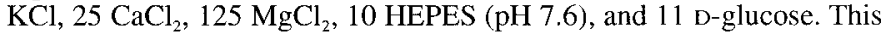
high divalent cation saline is different from that used by other researchers in portions of previous studies (Getting, 1981; Hume and Getting, 1982; Getting, 1983b), and appears to be more effective at preventing polysynaptic contributions to synaptic potentials. As a result, the shapes of some of the monosynaptic potentials that we will refer to here (Table 1) differ from those previously reported due to the lack of polysynaptic contributions to the synaptic potentials. In particular, the $\mathrm{C} 2$ to VSI-B connection was reported to be excitatory (Getting, 1983b). In normal 
saline, we also find that C2 excites VSI-B. However, in our high divalent cation saline, the monosynaptic potential is biphasic, with an initial small excitatory component followed by a prolonged and larger inhibitory component.

For all experiments where an accurate measure of membrane potential was required, the neuron being examined was impaled with two microelectrodes, one for current injection, the other for voltage recording. In other cases, current was injected through a balanced bridge circuit. Spikes in C2 and DSI were evoked using short depolarizing current pulses (5-20 msec). Each current pulse evoked a single spike, allowing the spike frequency to be precisely controlled. Data were recorded on VCR tape and analyzed off line. Portions of experiments were directly digitized using Cambridge Electronic Design hardware and software (SPIKE2). The digitization rate for intracellular recordings was $1 \mathrm{KHz}$ or greater. Traces produced from these recordings were sometimes signal averaged. Electrical noise was reduced through the use of a local-averaging routine on the digitized data, where consequtive $3-10 \mathrm{msec}$ segments were averaged, and in some traces $60 \mathrm{~Hz}$ electrical noise was digitally subtracted.

For measurements of paired-pulse facilitation, preparations were excluded if the amplitude of the LPSP evoked by a single C2 spike was not resolvable. In some preparations, tonic depolarization of $\mathrm{C} 2$ with current injection allowed single spike-evoked EPSPs to be resolved. The amplitude of the first EPSP (EPSP1) was measured from its peak to the baseline initially preceding the spike. If the baseline was not level, then the amplitude was measured from a linearly extrapolated baseline. The amplitude of the second EPSP (EPSP2) was corrected for summation by measuring from its peak to the corresponding time on a single EPSP (see Fig. 8A,B). The amount of facilitation was quantified as the facilitation index $(F i)$, which was defined as the relative size of EPSP2 with respect to EPSP1:

$$
F i=\frac{\text { EPSP2 }- \text { EPSP1 }}{\text { EPSPI }}
$$

Where applicable, two-tailed $t$ tests were used to determine statistical significance. Results are expressed as the mean \pm standard error of the mean.

\section{Results}

\section{DSI enhanced the size of C2-evoked EPSPS in DFN-A}

During a swim motor program, each of the six DSIs fires action potentials at rates over $20 \mathrm{~Hz}$ near the beginning of the swim and declining to $5-10 \mathrm{~Hz}$ by the end of the swim (Getting et al., 1980; Katz et al., 1994) (Fig. 1B). As previously shown (Katz et al., 1994), when a single DSI was stimulated to fire at a rate well within its natural spike frequency range for a swim, it caused the size of $\mathrm{C} 2$-evoked synaptic potentials recorded in the flexion neuron DFN-A to be enhanced two- to threefold (Fig. $2 A)$. We sought to determine if this enhancement was due to presynaptic actions of DSI on C2 or postsynaptic effects of DSI on DFN-A.

\section{Evidence against DSI acting at a postsynaptic site to enhance. the size of C2-evoked PSPS}

There were a number of potential postsynaptic mechanisms that could have contributed to the enhancement of the size of $\mathrm{C} 2$ synaptic potentials produced by DSI. These included changes in postsynaptic input resistance or a dependence of the $\mathrm{C} 2$-evoked EPSP on postsynaptic membrane potential. We tested for both possibilities and found that they did not play a role in the increasing the size of the C2-evoked EPSP.

Postsynaptic input resistance. If DSI stimulation increased the input resistance of DFN-A, it would cause the EPSPs evoked by $\mathrm{C} 2$ to become larger. Previous work reported a small increase in input resistance in DFN-A following DSI stimulation (Hume and Getting, 1982). However, in the present study, by using two electrodes in DFN-A and leveling the baseline by subtracting the EPSP waveform (Fig. 2B,C), we found no change in input
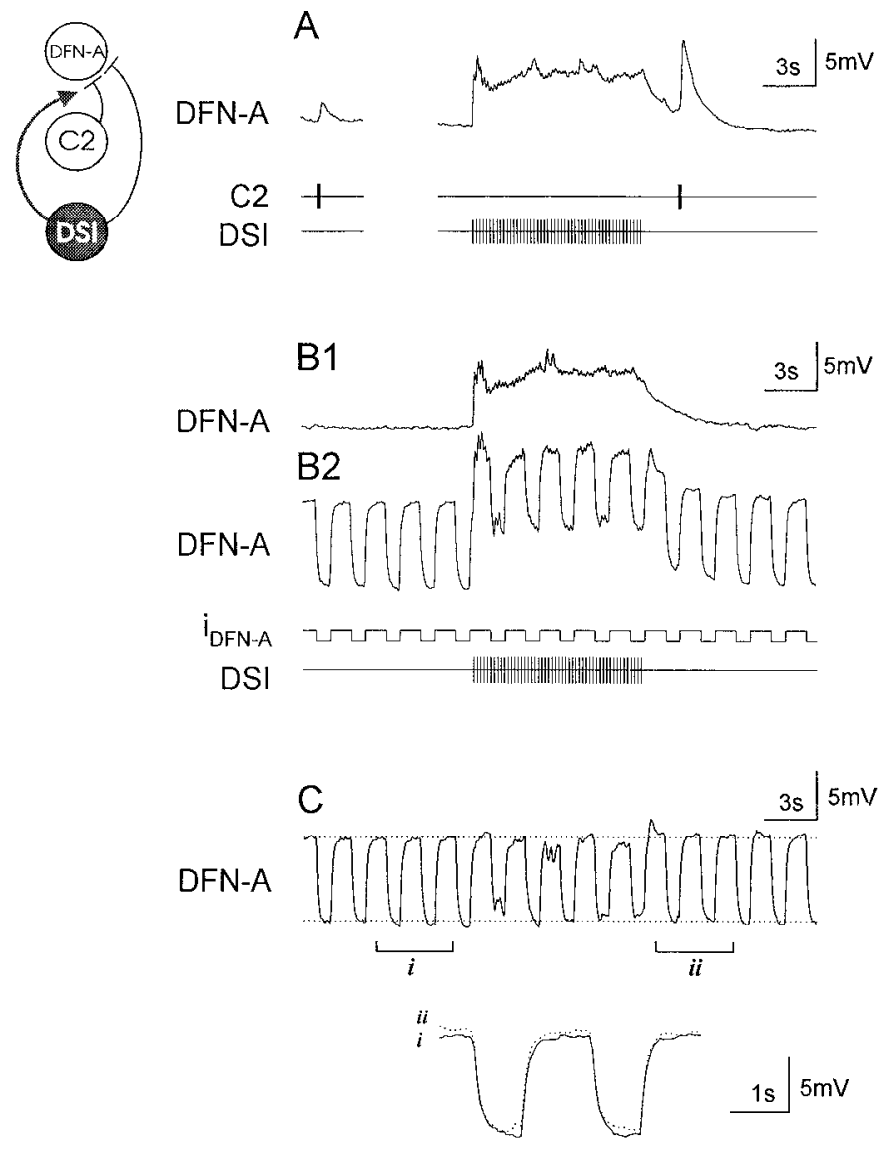

Figure 2. Enhancement of the size of the C.2 to DFN-A EPSP by DSI was not associated with an increase in DFN-A input resistance. $A$, When $\mathrm{C} 2$ was stimulated alone (four pulses, $20 \mathrm{~Hz}$ ), it evoked a small summated EPSP in DFN- $\Lambda$. Two seconds after DSI stimulation $(5 \mathrm{~Hz}, 10$ $\mathrm{sec})$, the same C2 spike train evoked a much larger EPSP in DFN-A. $B$, The synaptic potentials evoked by a DSI train were not associated with a large change in input resistance in DFN-A. B1, DSI was stimulated alone $(5 \mathrm{~Hz}, 10 \mathrm{sec})$ to evoke rapid, one-for-one EPSPs and a slowly decaying synaptic potential in DFN-A. B2, The above procedure was repeated while injecting hyperpolarizing current pulses into DFNA. The changes in the amplitude of the voltage deflections due to DSIevoked conductance changes were difficult to observe due to the shifting baseline. $C$, Subtraction of the DFN-A trace in $B I$ from that in $B 2$ reveals the responses to current pulses without the shift in baseline caused by the DSI-evoked EPSPs. There was a slight decrease in input resistance during the DSI stimulus train. Immediately following DSI stimulation (ii), when C2-evoked EPSPs would be modulated, there is no difference in input resistance when compared to the beginning of the trace $(i)$. The bottom traces are superimposed expansions of the two regions denoted by the brackets. In all cases, the prestimulus resting membrane potential of the DFN-A was $-70 \mathrm{mV}$. This and all subsequent figures are from preparations superfused with high divalent cation saline.

resistance during the period following DSI stimulation $(N=5)$. This indicates that the increase in the size of C2-evoked EPSPS during this period is probably not due to a change in postsynaptic input resistance. However, we cannot eliminate the possibility that DSI caused a change in input resistance of DFN-A at a synaptic site too distant from our soma recording site to be detected.

Postsynaptic membrane potential. Another possibility is that the large increase in the amplitude of the C2 to DFN-A EPSP caused by DSI is due to a voltage-dependent process. This might occur through a voltage dependence of either postsynaptic mem- 


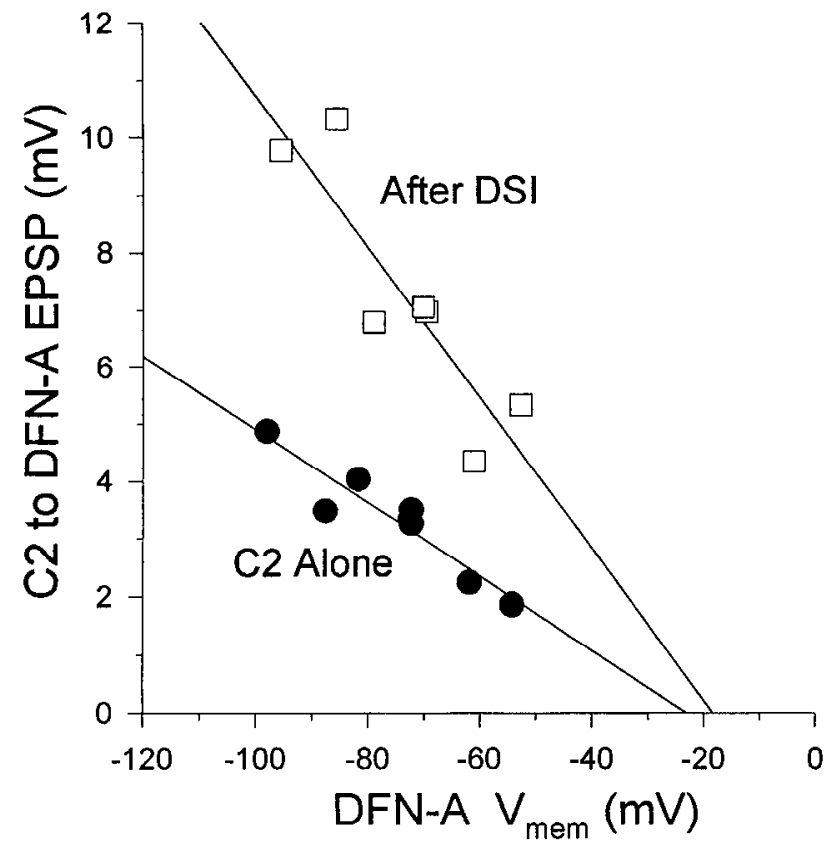

Figure 3. DSI enhancement of the size of C2 to DFN-A EPSPs did not exhibit voltage sensitivity. The initial membrane potential of DFN-A was altered by current injection through a second microelectrode in DFN-A. C2 was stimulated (four spikes at $20 \mathrm{~Hz}$ ) either alone or $2 \mathrm{sec}$ after a DSI train $(5 \mathrm{~Hz}, 10 \mathrm{sec})$. The amplitude of the $\mathrm{C} 2$ to DFN-A EPSP increased as DFN-A was hyperpolarized due to an increase in driving force. DSI stimulation enhanced the amplitude of those EPSPs at all membrane potentials. The reversal potentials for the $\mathrm{C} 2$-evoked EPSPs when C2 was stimulated alone (solid circles) or when C2 was stimulated after DSI (open squares) were extrapolated using a linear regression least-squares fit to the data, and were not substantially different. The data are from a single preparation.

brane conductances or the transmitter-gated conductance itself. Alternatively, it might occur through a change in driving force caused by a simple depolarization if the C2 to DFN-A EPSP were due to a conductance decrease, or even through the secondary activation of another postsynaptic receptor. To determine if any of these mechanisms play a role in the enhancement of the size of C2-evoked PSPs by DSI, we varied the membrane potential of the postsynaptic target of $\mathrm{C} 2$ using a separate current injection electrode and measured the response to $\mathrm{C} 2$ stimulation alone and after DSI stimulation (Fig. 3).

The results showed that the increase in FPSP amplitude caused by DSI stimulation was not dependent upon the membrane potential of the DFN-A $(N=4)$, indicating that it was not due to a change in synaptic driving force or a voltage-dependent effect. In all four experiments, the percentage increase in the C2-evoked EPSP caused by DSI stimulation was not changed by altering the membrane potential of the DFN-A even though the driving force on the EPSP varied with membrane potential. If the DSI-evoked enhancement of synaptic potentials were caused by a change in driving force through a simple change in the postsynaptic membrane potential, then the enhanced EPSP amplitudes would have fallen along the same line as the control amplitudes, which they did not. If the modulation or the EPSP amplitude had depended on postsynaptic voltage, then either or both of the two plots in Figure 3 would not have been linear. Instead, we found that the data from all experiments were well fit by linear regressions.

Further evidence that the enhancement of the C2 to DFN-A EPSP amplitude was not due to a change in driving force or a change in the mixture of conductances underlying the EPSP is that the reversal potential of the EPSP was not affected by DSI stimulation. When $\mathrm{C} 2$ was stimulated alone, the extrapolated reversal potential of the EPSP evoked in DFN-A was $-25.6 \pm$ $5.9 \mathrm{mV}$. The reversal potential for the C2-evoked PSP did not change significantly following DSI stimulation, the average reversal potential being $-24.6 \pm 3.9 \mathrm{mV}(N=4)$ (for example, see Fig. 3). Instead what was observed was an increase in the slope of the relationship of EPSP amplitude to DFN-A membrane potential (Fig. 3), suggesting that DSI stimulation resulted in a larger synaptic conductance evoked by $\mathrm{C} 2$.

\section{DSI differentially modulated synapses onto DFN-A}

It was further expected that if DSI acted postsynaptically to enhance the size of the C2 to DFN-A EPSP, then the amplitudes of synaptic potentials evoked by other presynaptic neurons might also show an increase. We found that this was not the case. In fact, using the same stimulus paradigm that caused an increase in C2-evoked EPSPs (Fig. 4A), stimulation of one DSI decreased the amplitude of EPSPs evoked by other DSIs onto DFN-A (Fig. 4B). Single DSI-evoked EPSPs decreased an av-
Figure 4. DSI stimulation differentially modulated inputs to DFN-A. $A$, $\mathrm{C} 2$ was stimulated to fire five spikes at $5 \mathrm{~Hz}$ cither alone or $2 \mathrm{sec}$ after a spike train in DSI-B ( $5 \mathrm{~Hz}, 10 \mathrm{sec})$. DSI-B stimulation increased the amplitude of the summated EPSP as well as the individual EPSPs. The pre-DSI stimulus DFN-A membrane potential was -66 $\mathrm{mV}$ for both traces. $B$, In the same preparation, DSI-A was stimulated in the same manner as $\mathrm{C} 2$ : either alone or following a spike train in DSI-B. In this case, DSI-B stimulation caused a decrease in the amplitudes of the individual fast EPSPs evoked by DSI in DFN-A as well as in the summated slow EPSP. The prestimulus DFN-A membrane potential was $-55 \mathrm{mV}$ for both traces.

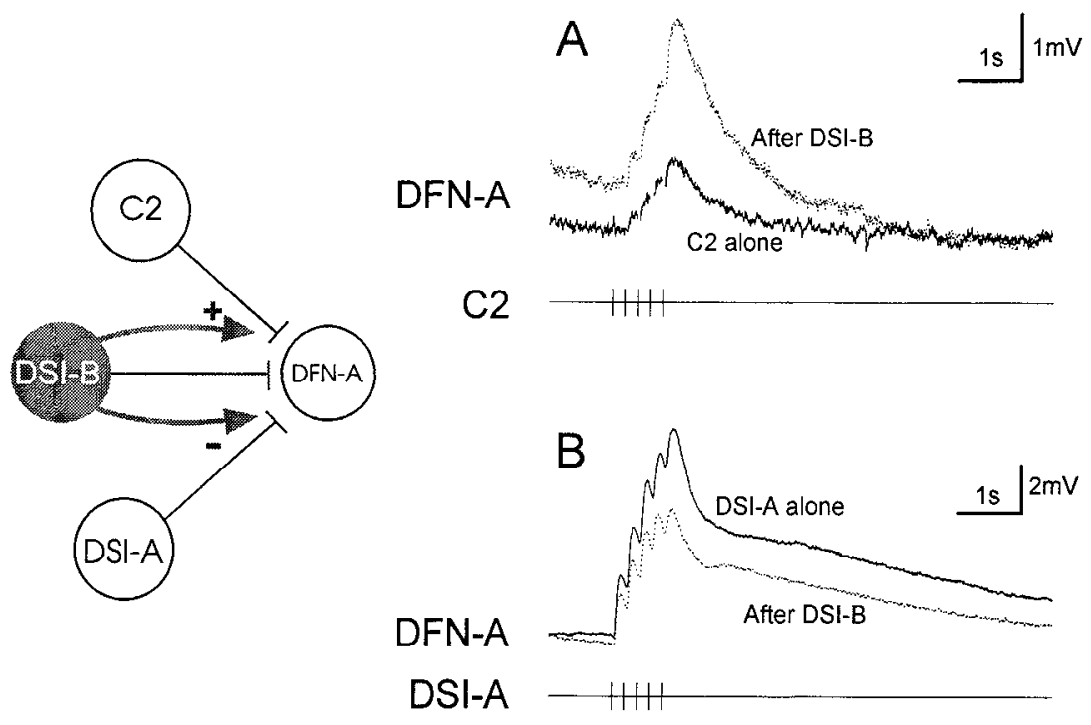


B
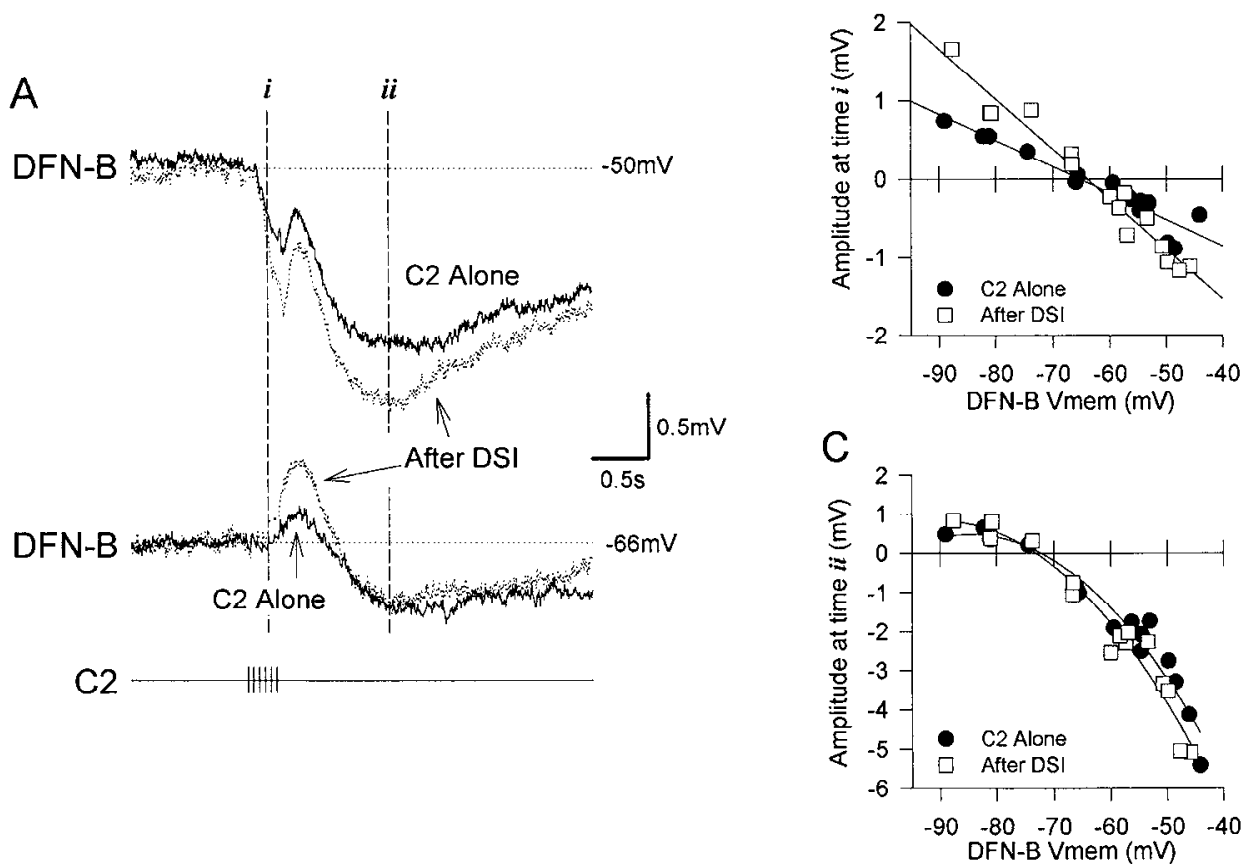

Figure 5. The amplitudes of all of the components of the C2 to DFN-B synaptic potential were enhanced by DSI stimulation. A, C2 stimulation (six spikes, $20 \mathrm{~Hz}$ ) evoked a triphasic synaptic potential in DFN-B. At a resting potential of $-50 \mathrm{mV}$ (DFN-B, top traces), there was an initial inhibitory component followed by a depolarizing peak, and ending with a prolonged hyperpolarization. DSI stimulation $(5 \mathrm{~Hz}, 6 \mathrm{sec})$, ending $4 \mathrm{sec}$ before the $\mathrm{C} 2$ stimulation, appeared to increase the sizes all three components. At a resting potential of $-66 \mathrm{mV}$ (lower DFN-B traces), the initial inhibitory component was at its reversal potential and the size of the excitatory component was clearly enhanced by DSI stimulation. $B$ and $C$, The amplitudes of the $(B)$ initial inhibitory component (measured at the time shown by $i$ in $A$ ) and $(C$ ) the slow inhibitory component (measured at the time shown by $i i$ in $A$ ) plotted versus DFN-B membrane potential when C2 was stimulated alone (solid circles) and when C2 was stimulated after DSI (open squares). DSI stimulation enhanced the amplitude of the fast IPSP at all membrane potentials but did not change its reversal potential. DSI slightly enhanced the amplitude of the slow IPSP and also produced no change in its reversal potential.

erage of $34.4 \pm 4.5 \%$ when preceded by stimulation of another DSI $(5 \mathrm{~Hz}, 10 \mathrm{sec})$. The decrease was seen at all seven synapses examined in four different preparations and was statistically significant $(t=3.74, P<0.01$ ). This differential modulation by DSI of the synaptic potentials evoked by C2 and DSI suggests a presynaptic site for the modulation of at least one of these synapses.

DSI enhanced the amplitude of all of C2's chemical synapses in the swim network

We had previously examined the effects of DSI stimulation on C2-evoked synaptic potentials in other DSIs and in DFN-A (Katz et al., 1994). We extended this work to examine the effect of DSI stimulation at $\mathrm{C} 2$ connections onto all other known postsynaptic targets in the swim network. In addition to its connections with DSI and DFN-A, C2 also synapses with the ventral swim interneurons of the CPG (VSI-A, VSI-B) and with the other efferent flexion neurons (DFN-B and VFN) (Getting et al., 1980; Getting, 1981, 1983b; Hume and Getting, 1982). DSI stimulation enhanced the amplitude of $\mathrm{C} 2$ synaptic potentials recorded in each of these postsynaptic targets (Table 1).

Some of C2's monosynaptic effects are excitatory, others are inhibitory, and some are mixed excitatory/inhibitory (Getting, 1981; Snow, 1982b). DSI stimulation increased the amplitude of all of these monosynaptic connections, regardless of their sign (Table 1). This indicates that the modulatory effect is not specific for a certain type of postsynaptic receptor. For example, C2 evoked a triphasic response in DFN-B (Fig. $5 A$ ). There was an initial fast inhibitory component with a reversal potential of about $-65 \mathrm{mV}$, which is near $E_{\mathrm{Cl}}$ for molluscan neurons (Kerkut and Meech, 1966; Ascher et al., 1976) (Fig. 5A,B). This fast inhibition was followed by a depolarizing potential (Fig. $5 A$ ). Finally, there was a prolonged inhibitory potential that rectified at potentials below about $-75 \mathrm{mV}$ or $E_{\mathrm{K}}$ (Kehoe, 1972) (Fig. $5 A, C)$ as has been seen for other transmitter-evoked potassium conductances in mollusks (Katz and Levitan, 1993; Kehoe, 1994). At a resting potential of $-50 \mathrm{mV}$, DSI stimulation $(5 \mathrm{~Hz}$, 6 sec) enhanced the size of hoth inhibitory components, but its effect on the excitatory component was obscured by the enlarged inhibitory components (Fig. 5A, top). However, by adjusting the membrane potential of DFN-B to $E_{\mathrm{Cl}}$, the first inhibitory component could be nullified, revealing that DSI stimulation also enhanced the amplitude of the excitatory component (Fig. $5 \mathrm{~A}$, lower DFN-B trace). Similar results were obtained for all three C2 to DFN-B synapses examined.

DSI enhancement of C2 synaptic strength did not depend on the type of synapse made by DSI onto the target of $C 2$

DSI itself synapses with many of the targets of C2 (Table 1). As with C2, the synaptic action of DSI at each of these synapses varies in sign. Regardless of whether DSI excited or inhibited the postsynaptic target of $\mathrm{C} 2$, it still increased the amplitude of synaptic potential evoked by $\mathrm{C} 2$ onto that target (Table 1). DSI even enhanced the size of $\mathrm{C} 2$ synaptic potentials at targets with which DSI itself did not synapse. For example, DSI did not evoke synaptic potentials in a Type IV neuron (Hume et al., 1982) (Fig. 6), yet it enhanced the size of the IPSP evoked by $\mathrm{C} 2$ in this cell (Fig. 6). This result again suggests that DSI pro- 
Figure 6. DSI enhanced the size of C2 synaptic potentials regardless of their sign or whether DSI itself synapses with that target. C2 stimulation evoked an EPSP in DFN-A and an IPSP in a Type IV neuron (Hume et al., 1982). DSI stimulation evoked one-forone EPSPs in DFN-A, but had no conventional synaptic effect on the Type IV neuron. DSI stimulation enhanced the sizes of the C2-evoked EPSP onto both targets. The prestimulus membrane potential was $-72 \mathrm{mV}$ for the DFN-A and $-38 \mathrm{mV}$ for the Type IV neuron.
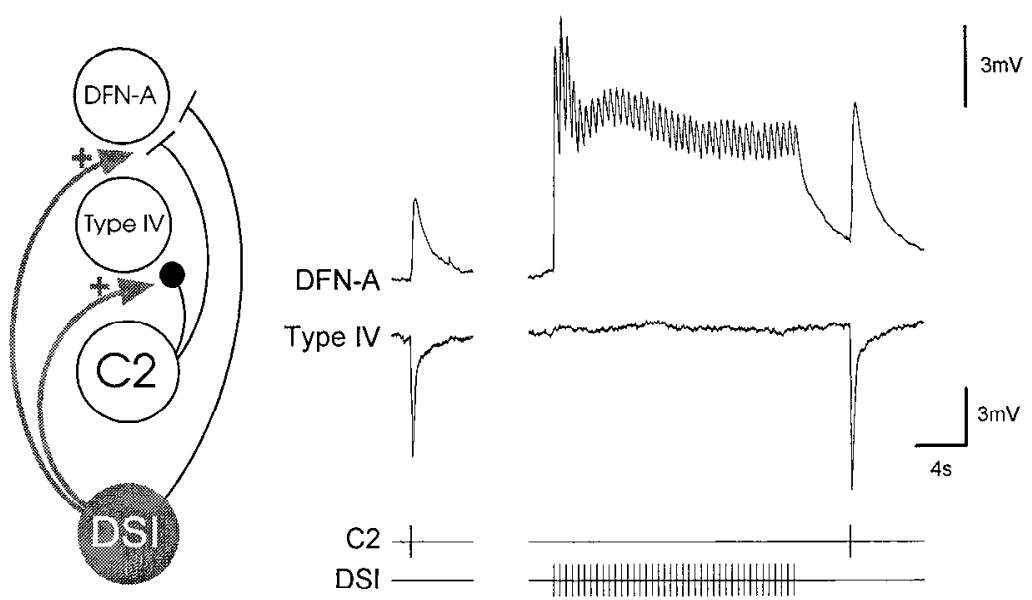

duces its modulatory effect by acting presynaptically on $\mathrm{C} 2$ rather than postsynaptically on each of the many target neurons of C2.

\section{DSI stimulation did not enhance the strength of electrical coupling between the two contralateral $\mathrm{C} 2 \mathrm{~s}$}

While DSI strongly enhanced the strength of all of the chemical synapses made by $\mathrm{C} 2$, it had no effect on the electrotonic synapse made by $\mathrm{C} 2$ onto its contralateral homolog. We applied repeated hyperpolarizing current pulses to one $\mathrm{C} 2$ and measured the amplitude of the electrotonic potentials in its contralateral homolog during DSI stimulation. Although there was a small decrease in the electrically coupled potentials during DSI stimulation, probably duc to shunting associated with the conventional EPSP evoked by DSI onto $\mathrm{C} 2$, no change in $\mathrm{C} 2$ to $\mathrm{C} 2$ electrical coupling was observed during the period following DSI stimulation, when the size of $\mathrm{C} 2$ chemical synapses was enhanced $(N=3$, Fig. $7 A)$.

To further test whether DSI stimulation affected C2-electrical coupling, we examined the electrotonic potentials produced by one $\mathrm{C} 2$ in the contralateral $\mathrm{C} 2$ while simultaneously monitoring the chemical synapse from $\mathrm{C} 2$ to DFN-A (Fig. $7 B$ ). Although the chemical EPSP recorded in DFN-A increased over two and a half fold in amplitude following DSI stimulation, the electrotonically coupled spikes in the contralateral $\mathrm{C} 2$ were almost completely unchanged from control $(N=2)$ (Fig. $7 B$ ).

\section{DSI stimulation enhanced paired-pulse facilitation by $C 2$ : a presynaptic site of action}

To conclusively determine if DSI enhancement of C2 synaptic strength was due to a presynaptic action on $\mathrm{C} 2$, we examined the effect of DSI on homosynaptic facilitation of C.2 to DFN-A EPSPs using a paired-pulse protocol. Paired-pulse facilitation has been shown in other systems to be due to presynaptic mechanisms and has been attributed to calcium influx from the first spike increasing the amount of transmitter released by the second spike (del Castillo and Katz, 1954; Katz and Miledi, 1968; Sarrazin, 1987; Zucker, 1989; Wu and Saggau, 1994). The one way in which paired-pulse facilitation could be due to a postsynaptic mechanism would be if the amplitude of the EPSP was strongly voltage dependent. Since the C2-evoked EPSPs were not voltage dependent (see Fig. 3), any mechanism that affects facilitation must be acting on the presynaptic terminal.

We found that the C2-evoked EPSPS recorded in DFN-A exhibited paired-pulse facilitation (Fig. 8A). When $\mathrm{C} 2$ was stim- ulated alone, with a $100 \mathrm{msec}$ interval between spikes, the average facilitation index ( $F i$; see Materials and Methods) was $1.15 \pm 0.88(N=3)$. If DSI acted purely postsynaptically, then the amplitudes of the first and second EPSPs would increase proportionally and $F i$ would remain unchanged. However, we found this not to be the case; in each of three preparations, following DSI stimulation ( $5 \mathrm{~Hz}, 10 \mathrm{sec}$ ), both the first and second C2 to DFN-A EPSPs increased in amplitude, but the size of the second EPSP increased by a larger percentage (Fig. $8 B$ ). As a result, $F i$ for a $100 \mathrm{msec}$ interval increased to an average of $6.83 \pm 3.08$ (Fig. $8 C$ ). This change in facilitation indicates that DSI acts presynaptically to enhance the amount of transmitter released from $\mathrm{C} 2$.

\section{DSI did not enhance transmitter release through a simple depolarization of $\mathrm{C} 2$}

In many molluscan neurons, including $\mathrm{C} 2$, tonic depolarization by current injection can increase the size of spike-evoked synaptic potentials (Shimahara and Tauc, 1975; Shapiro et al., 1980; Getting, 1981; Snow, 1982b). This may be due to an effect on calcium conductances in the cell (Shapiro et al., 1980). Since DSI directly depolarizes C2 with both rapid and long-lasting EPSPs (Getting, 1981), it seemed possible that DSI might depolarize the terminals of $\mathrm{C} 2$ more strongly than the soma. We sought to determine if this depolarization could be responsible for the enhancement of $\mathrm{C} 2$-evoked synaptic potentials. If the DSI-evoked enhancement of synaptic release were due to a simple depolarization of $\mathrm{C} 2$, then depolarizing current injected into the soma of $\mathrm{C} 2$ ought to compete with the effects of DSI stimulation.

C2 was tonically depolarized to varying degrees with constant current injection. The amplitude of the C2-evoked synaptic potentials were proportional to the resting membrane potential of C2 at the time that the spikes were evoked (Fig. 9). Within a defined range of depolarizations, this relationship was linear.

In the six preparations tested, DSI stimulation $(5 \mathrm{~Hz}, 10 \mathrm{sec})$ caused an increase in the amplitude of C2-evoked EPSPs regardless of the level of tonic depolarization of $\mathrm{C} 2$. The slopes of the relationships of $\mathrm{C} 2$-evoked PSP amplitude versus C2 membrane potential when $\mathrm{C} 2$ was stimulated alone and when C2 was stimulated following DSI stimulation indicate that DSIevoked modulation of $\mathrm{C} 2$ synaptic potentials was not competitive with depolarization from current injection (Fig. 9A). If the DSl-evoked enhancement of $\mathrm{C} 2$ synaptic amplitude were due to depolarization of $\mathrm{C} 2$, then the two lines would be parallel; DSI 

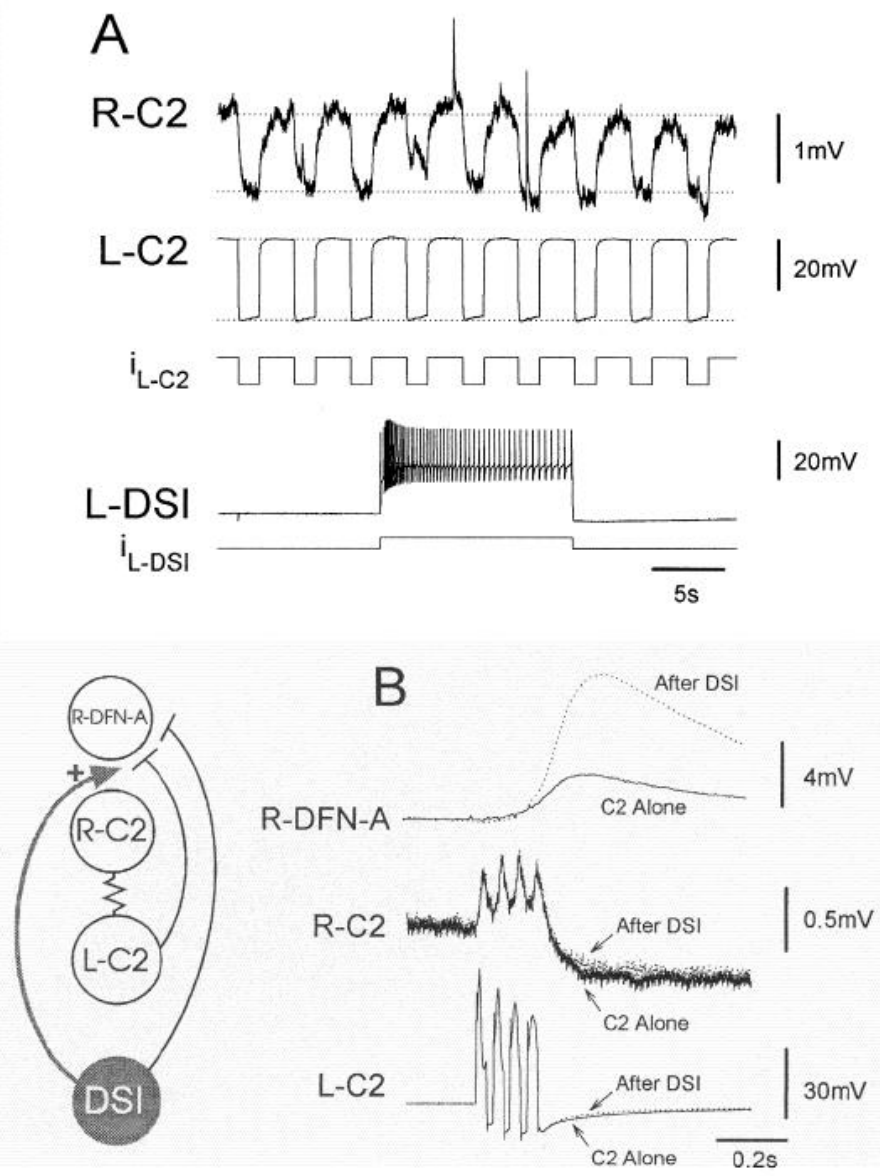

Figure 7. DSI did not enhance the strength of the electrical connection made by $\mathrm{C} 2$. $A$, The electrical coupling of the left $\mathrm{C} 2$ to the right $\mathrm{C} 2$ was tested by injecting repeated hyperpolarizing current pulses into the left $\mathrm{C} 2$. The amplitudes of the resulting voltage deflections in the right $\mathrm{C} 2$ are related to the input resistances of the two $\mathrm{C} 2 \mathrm{~s}$ and to the coupling resistance between them. DSI was injected with a step depolarizing current that caused DSI to fire at spike frequencies sufficient to enhance $\mathrm{C} 2$ synaptic strength. There was an initial decrease in the coupled potential recorded in the right $\mathrm{C} 2$. Following the DSI stimulation, there was no difference in electrical coupling. DSI makes synaptic connections only with the ipsilateral $\mathrm{C} 2$; therefore, it does not evoke one-forone synaptic potentials in the contralateral C2 (Getting, 1981). A similar lack of change in the amplitude of the coupled potentials was observed when current positive pulses were used or when current was injected into the right $\mathrm{C} 2$. Prestimulus resting potentials: R-C2, $-28 \mathrm{mV}$; L-C2, $-29 \mathrm{mV}$; L-DSI, $-41 \mathrm{mV}$. B. The electrotonically coupled spikes from the left $\mathrm{C} 2$ to the right $\mathrm{C} 2$ were not affected by DSI stimulation. C2 was stimulated with brief current pulses to fire four spikes at $20 \mathrm{~Hz}$ either alone (solid traces) or following DSI stimulation (dotted traces). The two sets of traces were overlaid. The four spikes in the left $\mathrm{C} 2$ resulted in four electrotonic potentials in the right C2 and an EPSP in the right DFN-A. DSI stimulation $(5 \mathrm{~Hz}, 10 \mathrm{sec})$ caused a large increase in the size of the chemical EPSP evoked in DFN-A. No change was seen in the electrically coupled potentials in the R-C2 or in the spikes evoked in the left $\mathrm{C} 2$. Prestimulus resting potentials for both sets of traces: R-DFN-A, $-70 \mathrm{mV}$; R-C2, $-28 \mathrm{mV}$; L-C2, $-22 \mathrm{mV}$.

would have caused a constant shift in the amount of depolarization needed to produce the various EPSP amplitudes. Instead, the two lines have different slopes, indicating that DSI uses a different mechanism than depolarization to enhance transmitter release from $\mathrm{C} 2$. Furthermore, current injection levels that saturated the depolarization-induced enhancement of C2-evoked EPSPs did not saturate the enhancement produced by DSI (not shown).

\section{Discussion}

The serotonergic DSIs are intrinsic components of the escape swim CPG circuit (Getting, 1981, 1989a), yet they also evoke neuromodulatory effects on other neurons in that same network; stimulation of a single DSI at physiological spike frequencies enhances the strength of synaptic actions by CPG neuron C2 (Katz et al., 1994). The results from this study show this synaptic enhancement is due to an increase in the amount of neurotransmitter released from $\mathrm{C} 2$ following DSI stimulation.

\section{DSI enhancement of the size of C2 synaptic potentials is not due to postsynaptic mechanisms}

Enhancement of C2-evoked synaptic potentials by DSI could have been caused by a presynaptic effect on $\mathrm{C} 2$, a postsynaptic effect on the targets of $\mathrm{C} 2$, or both pre- and postsynaptic actions. Although postsynaptic mechanisms have been shown to be involved in heterosynaptic enhancement of synaptic strength in other systems (Koerber and Mendell, 1991; Thompson et al., 1993), our results suggest that they are not playing any role in the enhancement caused by DSI. First, there is no significant change in postsynaptic input resistance to account for the two to three fold increase in synaptic strength. Second, the synaptic enhancement is not dependent upon the membrane potential of the postsynaptic neuron, and there is no change in the reversal potential of the C2-evoked PSPs.

If DSI enhanced the general responsiveness of the postsynaptic neuron, then the size of other inputs onto DFN-A might be expected to also be enhanced. Yet, we found that stimulation of one DSI decreases the amplitude of EPSPs evoked by other DSIs onto DFN-A. This by itself does not prove that DSI is acting presynaptically on both cells; we do not yet know if the effect on the synapses from other DSIs is presynaptic.

Although unlikely, it might also be the case that there is a specific increase in the responsiveness of DFN-A to the neurotransmitter released by $\mathrm{C} 2$. C2 is peptidergic and is immunoreactive for $\mathrm{SCP}_{\mathrm{B}}$ and FMRFamide (Snow, 1982a; Longley and Willows, 1985). A large molecular weight compound isolated from C2 mimics the multiphasic synaptic potentials onto at least one of its postsynaptic followers (Snow, 1982a). The identity of this compound is not yet known so we could not readily test whether DSI stimulation alters the responses to this substance. However, DSI stimulation does enhance the response of each postsynaptic target of $\mathrm{C} 2$ regardless of the sign of the synaptic response. These different responses, including multiphasic responses, are likely to be mediated by separate receptors. It seems unlikely that DSI would enhance the responses of each of those different receptors.

A further suggestion that DSI acts on C2 and not the postsynaptic followers of C2 is that DSI enhances the strength of $\mathrm{C} 2$ connections onto cells that DSI itself does not synapse with. While it is possible that DSI releases 5-HT in the vicinity of these cells and that these cells merely lack receptors which would produce voltage changes, the most parsimonious explanation is that DSI acts on $\mathrm{C} 2$ itself.

\section{DSI acts presynaptically to enhance transmitter release from C2}

The previously mentioned evidence only suggests that DSI acts to enhance transmitter release from $\mathrm{C} 2$. Due to the unknown anatomical organization of the synaptic sites, we chose not to attempt a quantal analysis to determine whether the action is presynaptic as has been done for other systems (Korn and Faber, 


\section{A C2 Alone}
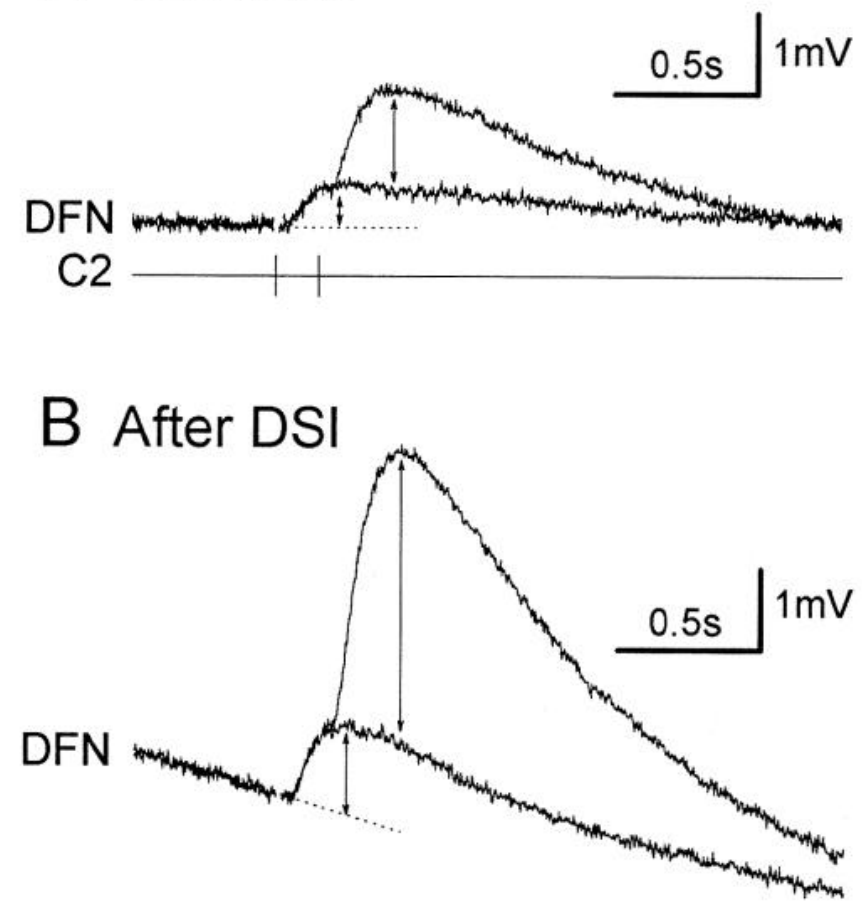

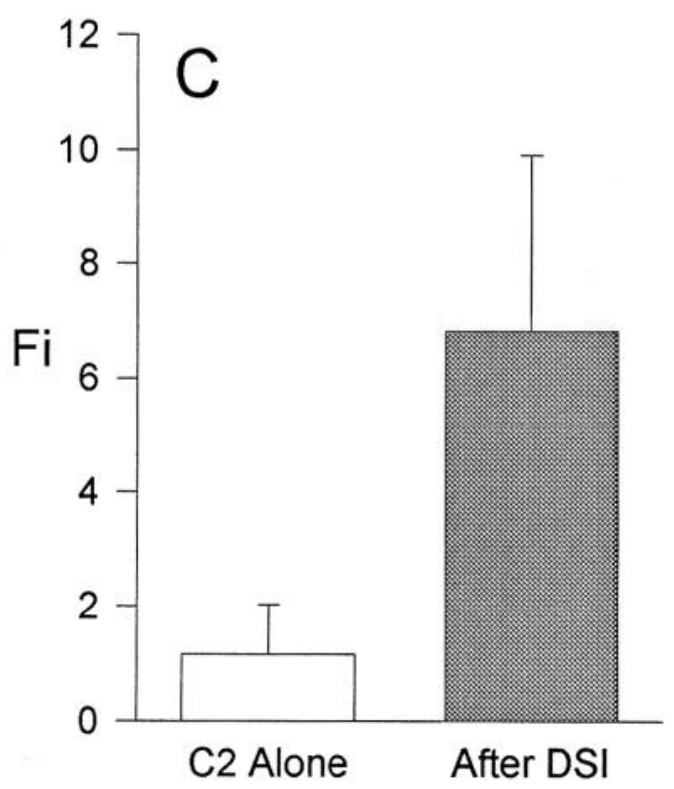

\section{$\mathrm{C} 2$}

Figure 8. DSI enhancement of the C2 to DFN-A EPSP amplitude was associated with an increase in C2 paired-pulse facilitation. A, When C2 was stimulated alone, it exhibited paired-pulse facilitation. Here, C2 was stimulated to fire two spikes 150 msec apart, evoking a pair of EPSPs in DFN-A. C2 was also made to fire a single spike, resulting in a unitary EPSP. The two traces were overlaid. The second EPSP was measured from its peak to the corresponding point on the first EPSP. The second EPSP was larger than the first, indicating facilitation. $B$, Two seconds after DSI stimulation $(5 \mathrm{~Hz}, 10 \mathrm{sec})$, the sizes of both EPSPs evoked by C2 were enhanced. The EPSPs are riding on the tail end of the slow component of the DSI to DFN-A EPSP. The first EPSP was measured from its peak to the linearly extrapolated baseline. The second EPSP was measured as in $A$. The amplitude of the second EPSP was enhanced to a greater extent than that of the first EPSP, indicating an increase in the amount of pairedpulse facilitation. The prestimulus resting potential for the DFN-A in both $A$ and $B$ was $-70 \mathrm{mV}$. $C$, The facilitation index, $F i$, which is a measure of the relative size of the second EPSP with respect to the first (see Materials and Methods), was calculated from three preparations with C2 interspike intervals of $100 \mathrm{msec}$. When $\mathrm{C} 2$ was stimulated alone, the average $F i$ was $1.15 \pm 0.88$. Following DSI stimulation, $F i$ increased to 6.83 \pm 3.08 .

1991; Mintz and Korn, 1991; Lisman and Harris, 1993). The strongest direct evidence that DSI acts presynaptically on C2 is that it affects the homosynaptic facilitation of C2-evoked EPSPs. Facilitation, measured using a paired-pulse paradigm, has been shown to be caused by a presynaptic mechanism where calcium entering the presynaptic terminal during the first spike enhances the release of neurotransmitter by the second spike (del Castillo and Katz, 1954; Katz and Miledi, 1968; Sarrazin, 1987; Zucker, 1989; Wu and Saggau, 1994). Anything that alters the amount of facilitation must be interfering with either calcium dynamics in the presynaptic terminal or calcium-triggered release.

Other studies have used alteration of paired-pulse facilitation as proof of a presynaptic locus for synaptic changes (Manabe et al., 1993; Christie and Abraham, 1994; Leung and Fu, 1994; Schulz et al., 1994). Usually, an enhancement of synaptic efficacy is associated with a decrease in facilitation. This is interpreted to indicate that the enhancement occurs through an increase in calcium entry, thus competing with the facilitation mechanism (Kumamoto, 1991). However, under certain conditions, synaptic enhancement has been associated with an increase in facilitation (Schulz et al., 1994). In this case, the mechanism underlying the enhancement is separate from that under- lying facilitation, perhaps involving a direct effect on the release mechanism itself.

While we do not yet know the mechanism underlying DSI enhancement of $\mathrm{C} 2$ synaptic potentials, we do know that DSI acts specifically on the chemical synapses of $\mathrm{C} 2$; it has no effect on the electrical connection made by $\mathrm{C} 2$. We have also shown that the enhancement of the chemical synapses is not due to a simple depolarization of $\mathrm{C} 2$. Thus a modulatory action directly affecting the release mechanism is possible.

\section{Enhancement of neurotransmitter release in other systems}

The DSIs are serotonergic (Katz and Frost, 1993; Katz et al., 1994; McClellan et al., 1994) and 5-HT has been shown to enhance the release of neurotransmitter in other systems. Two of the most studied examples are the effects of 5-HT on sensorimotor synapses in Aplysia (Kandel and Schwartz, 1982; Byrne et al., 1991; Klein, 1994) and crustacean neuromuscular synapses (Enyeart, 1981; Kravitz et al., 1981; Glusman and Kravitz, 1983; Delaney et al., 1991). In addition, 5-HT enhances the release of glycine from inhibitory synapses onto Mauthner cells (Mintz and Korn, 1991). Other neuromodulatory substances have also been shown to enhance release of neurotransmitters 

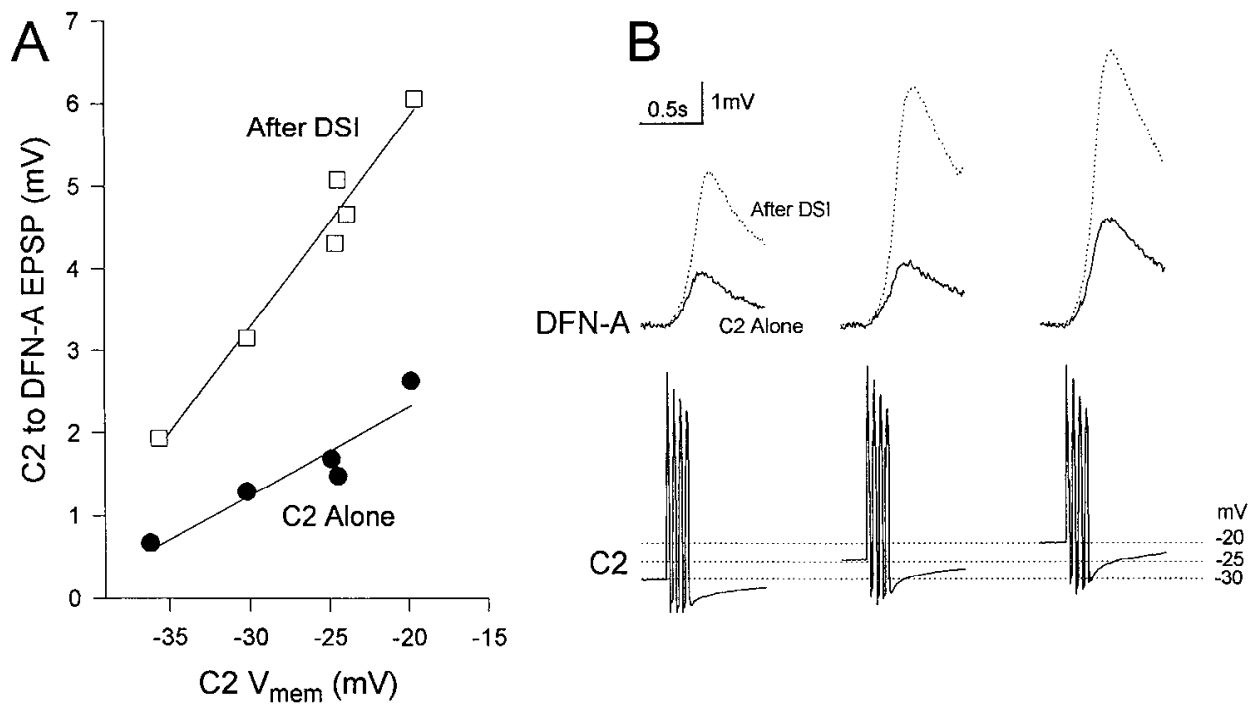

Figure 9. DSI enhancement of the size of C2-evoked EPSPs was not caused by a simple depolarization of C2. As seen with other molluscan neurons, the amplitude of C2-evoked synaptic potentials was dependent upon the resting membrane potential of the presynaptic neuron. Varying levels of current were injected into $\mathrm{C} 2$ through a second electrode, changing its resting membrane potential. The amplitude of EPSPs evoked by spikes in $\mathrm{C} 2$ increased with increasing depolarization of $\mathrm{C} 2 . \mathrm{A}, \mathrm{C} 2$ was stimulated alone (solid circles) or 2 sec after DSI stimulation (open squares). DSI stimulation $(5 \mathrm{~Hz}, 10 \mathrm{sec})$ increased the amplitude of C2-evoked EPSPs at all C2 membrane potentials. If DSI enhancement of C2-evoked EPSPs were caused by depolarization of $\mathrm{C} 2$, then the two curves would be parallel. Instead, they have different slopes. $B$, Sample traces showing $\mathrm{C} 2$ spikes and the resulting EPSPs in DFN-A when C2 was stimulated alone (solid traces), or following DSI stimulation (dotted traces). The C2 resting membrane potential for each pulse train is shown by the horizontal dotted lines. C2 spikes were elicited by four 20 msec constant current pulses from the various resting potentials. The prestimulus resting potential of the DFN-A was $-70 \mathrm{mV}$ for all traces.

(Langer, 1980; Libel, 1986; Chesselet, 1984; Starke et al., 1989; Wonnacott et al., 1989). For example, dopamine increases synaptic release from GABAergic neurons in the striatum (Cameron and Williams, 1993). In another CPG network, the stomatogastric nervous system, the peptide red pigment concentrating hormone ( $\mathrm{RPCH})$ and the biogenic amine octopamine appear to enhance release at some synapses, thereby altering the production of motor patterns (Dickinson, 1989; Johnson and HarrisWarrick, 1990; Dickinson et al., 1993).

Despite the many demonstrations of chemically induced pre synaptic enhancement of release, to our knowledge, the present study represents the first example of an individual neuron directly enhancing the release of neurotransmitter from an interneuron. In Aplysia, heterosynaptic facilitation has been demonstrated at a number of sensorimotor synapses in response to stimulation of modulatory neurons (Hawkins et al., 1981; Hawkins and Schacher, 1989; Mackey et al., 1989), but despite some suggestive results (Shimahara and Tauc, 1976), there has been no conclusive demonstration of this effect at interneuronal synapses in Aplysia. Evidence also strongly suggests that serotonergic enhancement of transmitter release demonstrated at synapses onto Mauthner cells in goldfish is likely to be caused by local 5-HT neurons (Mintz et al., 1989; Mintz and Korn, 1991). Furthermore, the vast literature showing the localization of the synaptic terminals of neurons containing modulatory substances at sites affected by those same neuromodulatory substances indicates that heterosynaptic enhancement of transmitter release is likely to be very important for many interneuronal circuits.

\section{The function of intrinsic neuromodulation in the Tritonia swim network}

The enhancement of neurotransmitter release from C2 by DSI is likely to be important for the Tritonia swim circuit, particularly for network reconfiguration. The swim network exists in at least two configurations: a single-shot reflexive withdrawal circuit and a rhythmic swim CPG circuit (Getting, 1977; Getting and Dekin, 1985a; Getting, 1989a,b). It has been suggested that the $\mathrm{C} 2$ neuron is important for the reconfiguration of the network into the oscillatory state (Getting and Dekin, 1985a,b), yet, in the rested state, before a swim has occurred, the synaptic connections made by $\mathrm{C} 2$ onto its CPG targets are all relatively weak and ineffective (unpublished data). Furthermore, C2 excitability prior to a swim is low (Frost et al., 1988). DSI activity rapidly enhances both C2's synaptic efficacy and its excitability (Katz and Frost, 1994). In the rested state, the DSIs exhibit a low rate of spontaneous firing, not enough to produce an enhancement of $\mathrm{C} 2$ synapses. When a swim stimulus arrives, the DSI neurons fire very rapidly. By quickly enhancing the strength of C2's connections and its excitability, DSI activity may functionally rewire the network and transform it so that $\mathrm{C} 2$ is in a position where it is able to evoke widespread effects, thus enabling the reconfiguration to occur. By acting presynaptically to enhance transmitter release from $C 2$ instead of postsynaptically to enhance responsiveness, DSI is able to preferentially enhance only the connections of $\mathrm{C} 2$. In fact, DSI decreases the connections strengths of other DSI neurons onto those same targets. Thus, DSI alters the balance of synaptic inputs to various targets. By enhancing transmitter release from specific synapses, intrinsic neuromodulation may participate in the transient "crystallization" of a functional neuronal circuit out of a diffuse network of anatomically connected neurons.

\section{References}

Ascher P, Kunze D, Neild TO (1976) Chloride distribution in Aplysia neurons. J Physiol (Lond) 256:441-464.

Barnes S, Syed NI, Bulloch AGM, Lukowiak K (1994) Modulation of ionic currents by dopamine in an interneurone of the respiratory central pattern generator of Lymnaea stagnalis. J Exp Biol 189:37-54.

Byrne JH, Baxter DA, Buonomano DV, Cleary LJ, Eskin A, Goldsmith 
JR, McClendon E, Nazif FA, Noel F, Scholz KP (1991) Neural and molecular bases of nonassociative and associative learning in Aplysia. Ann NY Acad Sci 627:124-149.

Cameron DL, Williams JT (1993) Dopamine D1 receptors facilitate transmitter release. Nature 366:344-347.

Chesselet M-F (1984) Presynaptic regulation of neurotransmitter release in the brain: facts and hypothesis. Neuroscience 12:347-375.

Christie BR, Abraham WC (1994) Differential regulation of pairedpulse plasticity following LTP in the dentate gyrus. Neuroreport $5: 385-388$

Cropper EC, Lloyd PE, Reed W, Tenenbaum R, Kupfermann I, Weiss KR (1987) Multiple neuropeptides in cholinergic motor neurons of Aplysia: evidence for modulation intrinsic to the motor circuit. Proc Natl Acad Sci USA 84:3486-3490.

Delaney K, Tank DW, Zucker RS (1991) Presynaptic calcium and serotonin-mediated enhancement of transmitter release at crayfish neuromuscular junction. J Neurosci 11:2631-2643.

del Castillo J, Katz B (1954) Statistical factors involved in neuromuscular facilitation and depression. J Physiol (Lond) 124:574-585.

Dickinson P (1989) Modulation of simple motor patterns. Semin Neurosci $1: 15-24$.

Dickinson PS, Mecsas C, Hetling J, Terio K (1993) The neuropeptide red pigment concentrating hormone affects rhythmic pattern generation at multiple sites. J Neurophysiol 69:1475-1483.

Enyeart J (1981) Cyclic AMP, 5-HT, and the modulation of transmitter release at the crayfish neuromuscular junction. J Neurobiol 12:505513.

Frost WN, Brown G, Getting PA (1988) Sensitization of the Tritonia escape swim: behavioral and cellular modifications. Soc Neurosci Abstr 14:607.

Gereau RW, Conn PJ (1994) Presynaptic enhancement of excitatory synaptic transmission by $\beta$-adrenergic receptor activation. J Neu rophysiol 72:1438-1442.

Getting PA (1977) Neuronal organization of escape swimming in Tritonia. J Comp Physiol A 121:325-342.

Getting PA (1981) Mechanisms of pattern generation underlying swimming in Tritonia. I. Neuronal network formed by monosynaptic connections. J Neurophysiol 46:65-79.

Getting PA (1983a) Neural control of swimming in Tritonia. In: Symposia of the Society for Experimental Biology, No. 37, Neural origin of rhythmic movements (Roberts A, Roberts BL, eds), pp 89-128. New York: Cambridge UP.

Getting PA (1983b) Mechanisms of pattern generation underlying swimming in Tritonia. III. Intrinsic and synaptic mechanisms for delayed excitation. J Neurophysiol 49:1036-1050.

Gelling PA (1989d) A network oscillator underlying swinnming in Tritonia. In: Neuronal and cellular oscillators (Jacklet JW, ed), pp 215 236. New York: Dekker.

Getting PA (1989b) Emerging principles governing the operation of neural networks. Annu Rev Neurosci 12:185-204.

Getting PA, Dekin MS (1985a) Tritonia swimming: a model system for integration within rhythmic motor systems. In: Model neural networks and behavior (Selverston AI, ed), pp 3-20. New York: Plenum.

Getting PA, Dekin MS (1985b) Mechanisms of pattern generation underlying swimming in Tritonia. IV. Gating of central pattern generator. J Neurophysiol 53:466-480.

Getting PA, Lennard PR, Hume RI (1980) Central pattern generator mediating swimming in Tritonia. I. Identification and synaptic interactions. J Neurophysiol 44:151-164.

Glusman S, Kravitz EA (1983) The action of serotonin on excitatory nerve terminals in lobster nerve-muscle preparations. J Physiol (Lond) 325:223-241.

Harris-Warrick RM (1988) Chemical modulation of central pattern generators. In: Neural control of rhythmic movements in vertebrates (Cohen AH, Rossignol S, Grillner S, eds), pp 285-331. New York: Wiley

Harris-Warrick RM, Marder E (1991) Modulation of neural networks for behavior. Annu Rev Neurosci 14:39-57.

Hawkins RD, Schacher S (1989) Identificd facilitator neurons L29 and L28 are excited by cutaneous stimuli used in dishabituation, sensitization, and classical conditioning of Aplysia. J Neurosci 9:42364245 .

Hawkins RD, Castellucci VF, Kandel ER (1981) Interneurons involved in mediation and modulation of gill-withdrawal reflex in Aplysia. II. Identified neurons produce heterosynaptic facilitation contributing to behavioral sensitization. J Neurophysiol 45:315-326.
Hume RI, Getting PA (1982) Motor organization of Tritonia swimming. II. Synaptic drive to flexion neurons from premotor interneurons. J Neurophysiol 47:75-90.

Hume RI, Getting PA, Del Beccaro MA (1982) Motor organization of Tritonia swimming. I. Quantitative analysis of swim behavior and flexion neuron firing patterns. J Neurophysiol 47:60-74.

Johnson BR, Harris-Warrick RM (1990) Aminergic modulation of graded synaptic transmission in the lobster stomatogastric ganglion. J Neurosci 10:2066-2076.

Jordan LM, Brownstone RM, Noga BR (1992) Control of functional systems in the brainstem and spinal cord. Curr Opin Neurobiol 2:794-801.

Kandel ER, Schwartz JH (1982) Molecular biology of learning: modulation of transmitter release. Science 218:433-443.

Katz B, Miledi R (1968) The role of calcium in neuromuscular facilitation. J Physiol (Lond) 195:481-492.

Katz PS, Frost WN (1993) Serotonin from DSI neurons acts as both a neurotransmitter and intrinsic ncuromodulator in the Tritonia cscape swim CPG circuit. Soc Neurosci Abstr 19:1700.

Katz PS, Frost WN (1994) Evidence that serotonergic neuromodulation intrinsic to the Tritonia swim CPG is due to presynaptic enhancement of release. Soc Neurosci Abstr 20:1201

Katz PS, Harris-Warrick RM (1990) Actions of identified neuromodulatory neurons in a simple motor system. Trends Neurosci 13:367373.

Katz PS, Levitan IB (1993) Quisqualate and ACPD are agonists for a glutamate-activated current in identified Aplysia neurons. J Neurophysiol 69:143-150.

Katz PS, Getting PA, Frost WN (1994) Dynamic neuromodulation of synaptic strength intrinsic to a central pattern generator circuit. Nature 367:729-731

Kehoe J (1994) Glutamate activates a $\mathrm{K}^{+}$conductance increase in Aplysia neurons that appears to be independent of $\mathrm{G}$ proteins. Neuron 13: 691-702.

Kehoe JS (1972) Ionic mechanisms of a two-component cholinergic inhibition in Aplysia neurons. J Physiol (Lond) 225:85-114.

Kerkut GA, Meech RW (1966) The internal chloride concentration of H and D cells in the snail brain. Comp Biochem Physiol 19:819832.

Klein M (1994) Synaptic augmentation by 5-HT al rested Aplysia sensorimotor synapses: independence of action potential prolongation. Neuron 13:159-166.

Koerber RH, Mendell LM (1991) Modulation of synaptic transmission at Ia-afferent fiber connections on motoneurons during high-frequency stimulation: role of the postsynaptic target. J Neurophysiol 65 : $590-597$.

Korn H, Faber DS (1991) Quantal analysis and synaptic efficacy in the CNS. Trends Neurosci 14:439 445 .

Kravitz EA, Glusman S, Livingstone MS, Harris-Warrick RM (1981) Serotonin and octopamine in the lobster nervous system: mechanism of action at neuromuscular junctions and preliminary behavioral studies. In: Serotonin neurotransmission and behavior (Jacobs BL, Gelperin A, eds), pp 189-210. Cambridge, MA: MIT Press.

Kumamoto E (1991) Short-term facilitation as a tool to know neuromodulator-induced change in $\mathrm{Ca}^{2+}$ movement in the nerve terminal. I Theor Biol 149:317-323.

Langer SZ (1980) Presynaptic regulation of the release of catecholamines. Pharmacol Rev 32:337--362.

Lcung LS, Fu X-W (1994) Factors affecting paircd-pulsc facilitation in hippocampal CA1 neurons in vitro. Brain Res 650:75-84.

Libet B (1986) Nonclassical synaptic functions of transmitters. Fed Proc 45:2678-2686.

Lisman JE, Harris KM (1993) Quantal analysis and synaptic anatomy-integrating two views of hippocampal plasticity. Trends Neurosci 16:141-147.

Longley RD, Longley AJ (1987) Evolution of behavior: an homologous peptidergic escape swim interneuron in swimming gastropod nudibranchs (Tritonia, Hermissenda) and a related non-swimming species (Aeolidia). Soc Neurosci Abstr 13:822.

Longley RD, Willows AOD (1985) Inmunocylochemical localization of serotonin, FMRFamide, BPP, and $\mathrm{SCP}_{\mathrm{B}}$ in nudibranch mollusks. Soc Neurosci Abstr 11:943.

Mackey SL, Kandel ER, Hawkins RD (1989) Identified serotonergic neurons LCB1 and RCB1 in the cerebral ganglia of Aplysia produce 
presynaptic facilitation of siphon sensory neurons. J Neurosci 9:4227-4235.

Manabe T, Wyllie DJA, Perkel DJ, Nicoll RA (1993) Modulation of synaptic transmission and long-term potentiation: effects on paired pulse facilitation and EPSC variance in the CA1 region of the hippocampus. J Neurophysiol 70:1451-1459.

Marder E (1994) Invertebrate neurobiology: polymorphic neural networks. Curr Biol 4:752-754.

McClellan AD, Brown GD, Getting PA (1994) Modulation of swimming in Tritonia: excitatory and inhibitory effects of serotonin. J Comp Physiol A 174:257-266.

Mintz I, Korn H (1991) Serotonergic facilitation of quantal release at central inhibitory synapses. J Neurosci 11:3359-3370.

Mintz I, Gotow T, Triller A, Korn H (1989) Effect of serotonergic afferents on quantal release at central inhibitory synapses. Science 245:190-192.

Nusbaum MP (1994) Presynaptic control of neurones in pattern-generating networks. Curr Opin Neurobiol 4:909-914.

Nusbaum MP, Weimann JM, Golowasch J, Marder E (1992) Presynaptic control of modulatory fibers by their neural network targets. J Neurosci 12:2706-2714.

Orchard I, Ramirez J-M, Lange AB (1993) A multifunctional role for octopamine in locust flight. Annu Rev Fntomol 38:227-249.

Sarrazin C (1987) Underlying mechanisms of facilitation and depression of transmitter release. The role of calcium in synaptic transmission. Neurol Res 9:249-258.

Schulz PE, Cook EP, Johnston D (1994) Changes in paired-pulse facilitation suggest presynaptic involvement in long-term potentiation. J Neurosci 14:5325-5337.

Shapiro E, Castellucci VF, Kandel ER (1980) Presynaptic membrane potential affects transmitter release in an identified neuron in Aplysia by modulating the $\mathrm{Ca}^{2+}$ and $\mathrm{K}^{+}$currents. Proc Natl Acad Sci USA 77:629-633.

Shimahara T, Tauc L (1975) Multiple interneuronal effects to the giant cells in Aplysia. J Physiol (Lond) 247:299-319.

Shimahara T, Tauc L (1976) Identification of a neuron inducing heterosynaptic facilitation on a specific synapse in Aplysia. Brain Res 118:142-146.
Sillar KT (1991) Spinal pattern generation and sensory gating mechanisms. Curr Opin Neurobiol 1:583-589.

Snow RW (1982a) Evidence for peptide-mediated neurotransmission in a molluskan brain. J Neurohiol 13:267-2.77.

Snow RW (1982b) Characterization of the synaptic actions of an interneuron in the central nervous system of Tritonia. J Neurobiol 13: 251-266.

Starke K, Gothert M, Kilbinger H (1989) Modulation of neurotransmitter release by presynaptic autoreceptors. Physiol Revs 69:864989.

Taghert PH, Willows AOD (1978) Control of a fixed action pattern by single, central neurons in the marine mollusk, Tritonia diomedea. $\mathrm{J}$ Comp Physiol 123:253-259.

Thompson SWN, Woolf CJ, Sivilotti LG (1993) Small-caliber afferent inputs produce a heterosynaptic facilitation of the synaptic responses evoked by primary afferent $\mathrm{A}$-fibers in the neonatal rat spinal cord in vitro. J Neurophysiol 69:2116-2128.

Watson AHD (1992) Presynaptic modulation of sensory afferents in the invertebrate and vertebrate nervous system. Comp Biochem Physiol [A] 103A:227-239.

Willows AOD, Hoyle G (1969) Neuronal network triggering of fixed action pattern. Science 166:1549-1551.

Willows AOD, Dorsett DA, Hoyle G (1973a) The neuronal basis of hehavior in Tritonia. III. Neuronal mechanism of a fixed action pattern. J Neurobiol 4:255-285.

Willows AOD, Dorsett DA, Hoyle G (1973b) The neuronal basis of behavior in Tritonia. I. Functional organization of the central nervous system. J Neurobiol 4:207-237.

Willows AOD, Lloyd PE, Masinovsky BP (1988) Multiple transmitter ncurons in Tritonia. III. Modulation of central pattern generator controlling feeding. J Neurobiol 19:69-86.

Wonnacott S, Irons J, Rapier C, Thorne B, Lunt GG (1989) Presynaptic Inodulation of transmitter release by nicotinic receptors. Prog Brain Res 79:157-163.

Wu LG, Saggau P (1994) Presynaptic calcium is increased during normal synaptic transmission and paired-pulse facilitation, but not in long-term potentiation in area $\mathrm{CA} 1$ of hippocampus. J Neurosci 14: 645-654.

Zucker RS (1989) Short-term synaptic plasticity. Annu Rev Neurosci $12: 13-31$. 